\title{
Digital Applications in Metals and Mining Industry
}

\author{
Sanjay Dehran, Pragati Agrawal, Praveen Midha
}

Fluor Daniel Corporation, Gurgaon, India

Email address:

sanjay.dehran@fluor.com(S.Dehran),pragati.agrawal@fluor.com(P.Agrawal),pk.midha@fluor.com(P.Midha)

\section{To cite this article:}

Sanjay Dehran, Pragati Agrawal, Praveen Midha. Digital Applications in Metals and Mining Industry. American Journal of Operations Management and Information Systems. Vol. 3, No. 1, 2018, pp. 33-37. doi: 10.11648/j.ajomis.20180301.15

Received: February 16, 2018; Accepted: March 16, 2018; Published: April 11, 2018

\begin{abstract}
The Industrial Internet of Things is opening opportunities for mining and metals companies to pursue visibility, safety, and efficiency like never before. There are many aspects of this industry that make it an ideal candidate for transformation. These include large physical environments, changing market and environmental conditions, and the massive size and amount of equipment. Additionally, the challenges of assessing asset conditions against maintenance schedules and logistical constraints must be met. The Industrial Internet of Things (IIoT) is at the heart of this transformation. It connects people, machines, items, and services to streamline the flow of information, enable real-time decisions, and open new opportunities in mining and metals. Leading companies are already investing billions in the Industrial Internet of Things and realizing returns that range from increased asset uptime and efficient predictive maintenance to autonomous fleets of vehicles able to move more goods. This paper will be talking about various digital applications available for the Metals and Mining industry. Companies can use advanced analytics to extract management-relevant information from the large amounts of unstructured data that they generate. This information can then be used to improve how mines are run and to make betterinformed and speedier decisions across the full range of the mining business processes. The applications start from design $\&$ engineering followed by supply chain management, production \& maintenance management, transport \& logistics management. This paper will briefly discuss about variety of enterprise level real time performance solutions in various fields of the Metals and Mining industry.
\end{abstract}

Keywords: Digitalization, Metals and Mining, Safety, Digital, Automation, IIoT, Engineering

\section{Introduction}

Existing market dynamics and challenges are forcing a massive change in the industry's approach to technology in all segments of the Metals and Mining industry. Since Mining is a very old business and it can be reluctant to embrace new technology, it is difficult to leave behind a suite of tried-and-true processes when you are focused on production and profits. However, the future of the industry lies with the full digitalization of the complete chain and the use of knowledge captured from connected devices for realtime optimization of processes and operations. The current digital era is about turning the data into action, which helps us increasing both the speed and quality of decision-making. Digitally connected assets can significantly reduce costs, shorten schedules and minimize risk. Today Industry has embraced all aspects of electrical, instrumentation, automation and telecoms to achieve completely integrated and digitally oriented performance enhancing solutions.

\section{Industry 4.0, Industrial Internet of Things}

Advancement in IT and telecommunication technology has widely influenced the automation across industries. There is a definite shift from the age old proprietary hardware and software systems towards more open universal hardware and software systems, which offer better interchangeability of automation products. With the advent of Industrial Internet of Things (IIOT) hundreds of millions, of individuals and businesses, with billions of smart, communicating devices will change the way we work, learn and innovate. This is the time to move from smart devices to smart services. Smart services is a concept in which inputs from machines, people, video streams, maps, newsfeeds, sensors etc is digitized and placed onto networks integrating people, devices, processes and content to enable collective awareness. Existing systems are not well integrated and the information they accumulate cannot be easily accessed across differing application 
systems. Better integration of engineering and manufacturing and interfaces among electronic and electro-mechanical elements are going to change the plants' planning, operations and maintenance in a big way.

Three reasons for mainstream application of this technology are

1. Proliferation of low cost, smaller sensors and chips that can be embedded in anything and can communicate over the Internet

2. Advanced analytics capabilities based on big data, statistical and cognitive models

3. Availability of scalable cloud architecture with secure connectivity, mobile access, data storage and connected ecosystem for managed services deployment

\section{IIoT Applications in Metals and Mining Industry}

The Digital Transformation is opening opportunities for mining and metals companies to pursue visibility, safety, and efficiency like never before. There are many aspects of these industries that make them ideal candidates for transformation. These include large physical environments, changing market and environmental conditions, and the massive size and amount of equipment. Additionally, the challenges of assessing asset conditions against maintenance schedules and logistical constraints must be met.

In order to take advantage of this technology broadly two things are required. First connect and collect real time information and second analyze and interact based on specific data conditions. Implementation of Industrial Internet of Things (IIoT) in the industry may be looked at that how granular, wireless, diverse and integrated we can go.

Following main categories of Applications shall be the main target.

\subsection{Safety}

In mining operations, operator safety is a major concern due to hazardous working conditions (blasting, dangerous gasses and moving equipment). IOT sensors (environment, location, motion and bio sensing) mounted on helmets; jackets of employees are part of infrastructure and communicate with other mining equipment like Dragline excavators, haul trucks, crushers, LHDs etc. to ensure employee safety. Potential application would be integrating people tracking, communications, video surveillance and analytics, real time personal health management, first responders' integration and weather forecast.

The Industrial Internet of Things (IIoT) can be manifested in vehicle collision avoidance systems, which include personnel and vehicle tags that can communicate wirelessly, and in trucks equipped with infrared, radar and video systems, all for the purpose of notifying operators of the presence of obstacles.

\subsection{Mine Adaptive Optimization}

One of the key challenges in the industry is that the ores, near-surface ores, are getting to be depleted, so we need to go further down. Miners will increasingly have to deal with the prospects of mining low-grade ores and turn to "more remote destinations and deeper deposits.

Mine Adaptive optimization would integrate Ore tracking, quality control, asset performance, mobile machine tracking, weather forecast, process controls, energy, fuel and water management.

The essence of the Industrial Internet of Things (IIoT) is connectivity, data and analytics. The operations of many mining companies span from pit to port. They use machines that range from simple to complex and rely on workers who spend time underground and in air-conditioned offices.

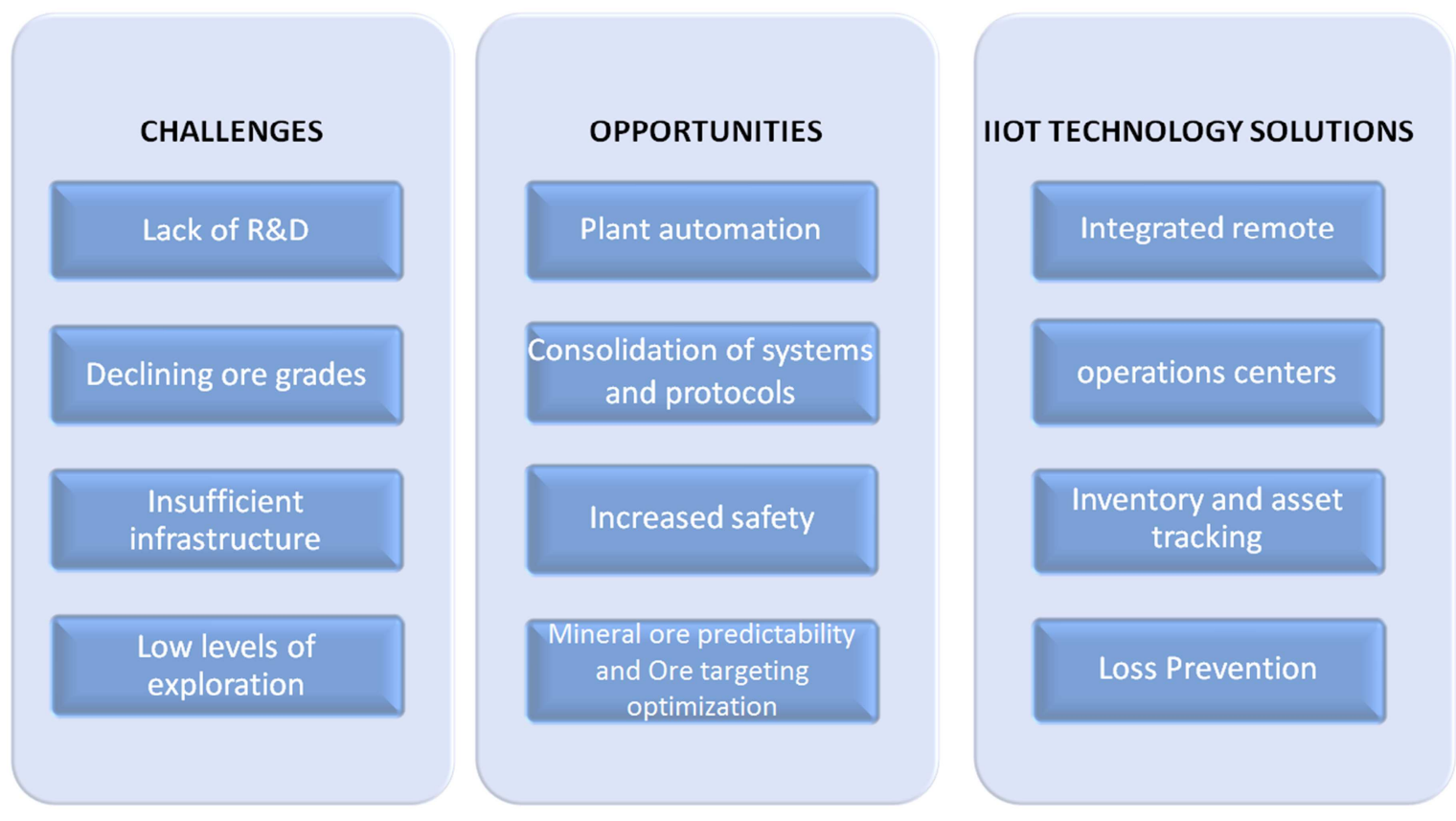

Figure 1. Challenges, opportunities and applications of Industrial Internet of Things (IIoT). 
There are a lot of inefficiencies in batch process underground mining. The utilization level for underground mining is at about $35 \%$ as compared to open pit or surface applications that are at maybe $70 \%$ or higher due to a more continuous process. If you're dealing with a valuable mineral, any nominal improvement in utilization will certainly help the bottom line. Simply put, the opportunity for optimization is huge.

The real changes that have to happen are akin to what happened in manufacturing. Compare a car plant in the 1970s with the car plant that Tesla uses to build its new car, there are sensors on everything today. There are robots doing everything. Mining today still looks like a car plant maybe in the late $70 \mathrm{~s}$, but not certainly not one in the $90 \mathrm{~s}$. Data are not fed together, and that's the key. Industrial Internet of Things (IIoT) with sensors, full data analytics, and automation capabilities will bring marked improvement to both mining productivity and efficiency just as it did for manufacturing.

\subsection{Other Applications}

The integrated nature of Industrial Internet of Things
(IIoT) solutions means that mining companies can seize all of the opportunities at once. For example, the driverless trucks will not just help improve safety, but it will increase productivity as the trucks will be operational for more hours.

Other applications are similar to rest of the industry like Transport/logistics related intelligence, improving the supply chain efficiencies, production facilities ERP level applications which provide real time updates enabling close coordination between various functions in the production facilities apart from improving energy \& maintenance efficiencies.

Companies can use advanced analytics to extract management-relevant information from the large amounts of unstructured data that they generate. This information can then be used to improve how mines are run and to make better-informed and speedier decisions across the full range of the mining business processes. The applications start from design \& engineering followed by supply chain management, production \& maintenance management, transport \& logistics management.

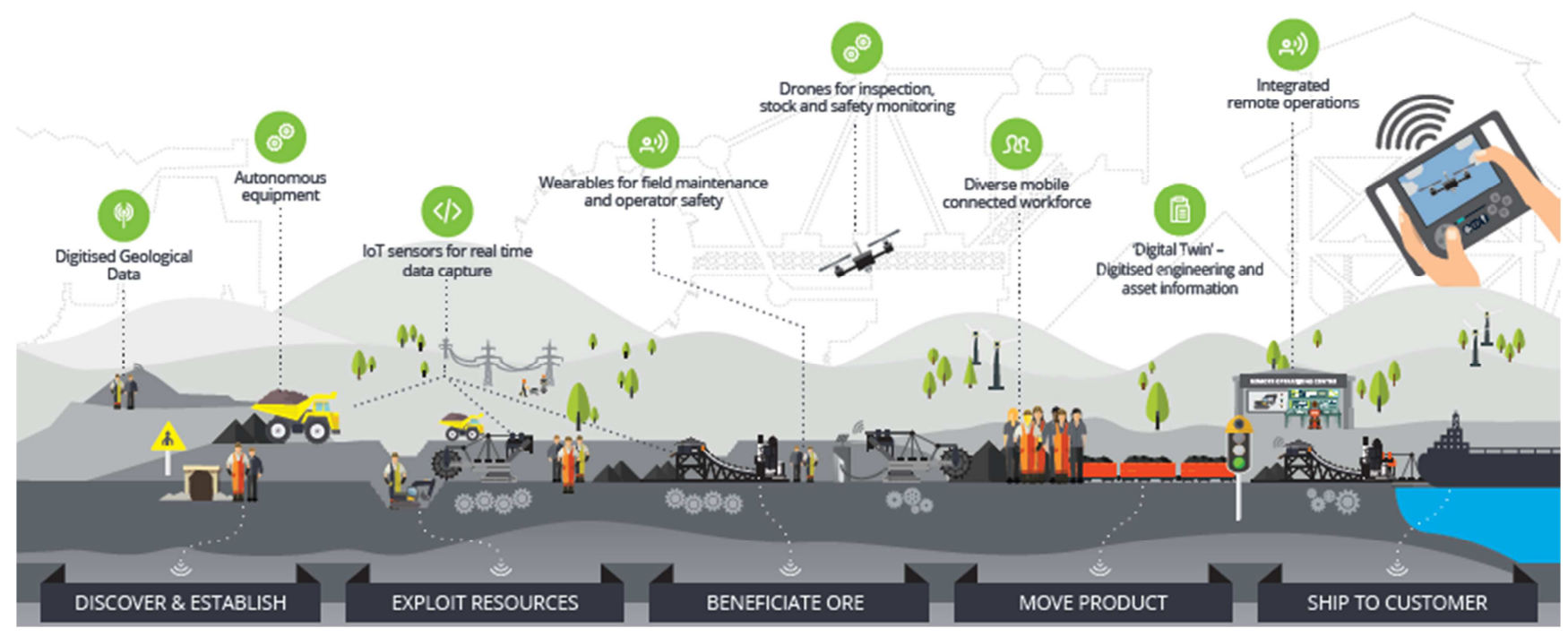

Figure 2. Integrated Operational Planning, Control and Decision Support.

\section{Financial Picture}

Today the world is getting geared up to adapt IOT to take early mover advantage, differentiate themselves and making the operations and processes smarter. As per a research from IDC, the worldwide resource industry of "Industrial Internet of Things" revenue opportunity is \$40 Billion by 2018 .
Morgan Stanley's blue paper "The interne to things is now: Connecting the Real Economy" suggests that there is potential market of \$100 Billion for autonomous vehicles for trucking and logistics, \$70 Billion for wearable technology market and potential saving of $\$ 168$ Billion in freight transportation by 2024 . 


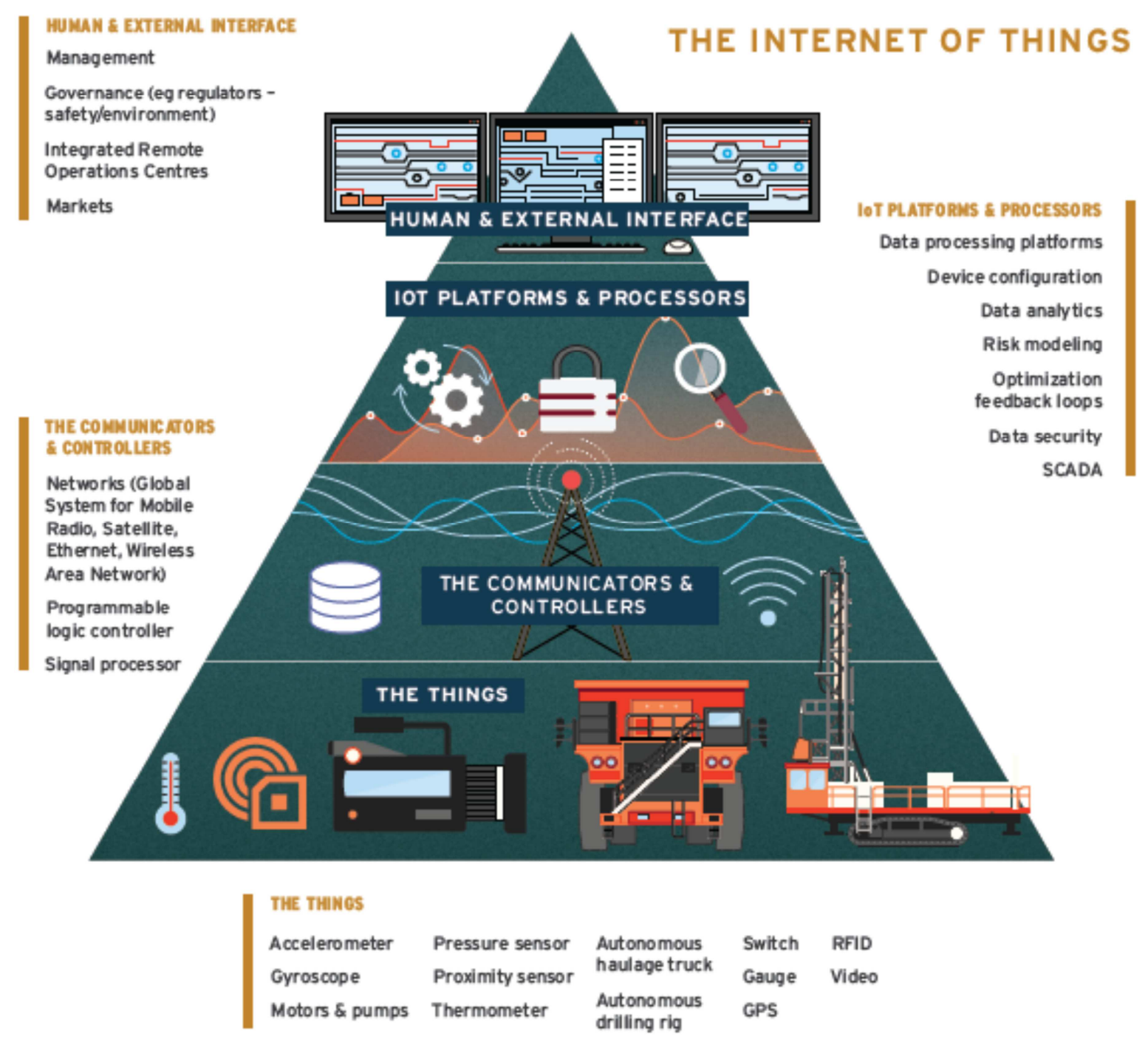

Figure 3. IIoT (Industrial Internet of Things) technologies in mining.

\section{Conclusion}

Industry 4.0, Industrial Internet of Things (IIoT) journey is about business model innovation. We are at the beginning of this journey and to get started we must take a business benefit driven approach. This means to first solve existing problems, that were not properly solved in the past and then to innovate on the above principles driving innovation. Macro-Economic drivers are working in favor of Industrial Internet of Things \& expected impact of $\$ 6.2$ trillion by 2025 .

\section{References}

[1] World Economic Forum. (2009). Mining \& Metals: Scenarios to 2030 . Retrieved from

http://www.weforum.org/reports/mining-metals-scenarios2030.

[2] Dassault Systems GEOVIA. (2014). Special Report on Mining Innovation. Retrieved from

http://www.gemcomsoftware.com/special_report.
[3] Duffy, P. (2013). Beyond MQTT: A Cisco View on IoT Protocols. Cisco Blogs. Retrieved from $\mathrm{http} / / /$ blogs.cisco.com/ioe/beyond-mqtt-acisco-view-on-iotprotocols/.

[4] Innovative Technologies and Concepts for the Intelligent Deep Mine of the Future. (2013). Machines to optimize exploitation. Retrieved from

http://www.i2mine.eu/content/open_access/machinesoptimise-exploitation.

[5] Frost \& Sullivan. (2014, June 19). Industry Scorecard for the Global Mining Industry: Strategic Analysis of the Top Industry Trends and Evaluation of Key Growth Opportunities. Retrieved from http://www.frost.com/prod/servlet/reportbrochure.pag?id=NCDF-01-00-00-00.

[6] Frost \& Sullivan. (2014, June 19). Industry Scorecard for the Global Mining Industry: Strategic Analysis of the Top Industry Trends and Evaluation of Key Growth Opportunities. Retrieved from http://www.frost.com/prod/servlet/reportbrochure.pag?id=NCDF-01-00-00-00.

[7] Regalado, A. (2014, May 20). GE's \$1 Billion Software Bet. MIT Technology Review. Retrieved from http://www.technologyreview.com/news/527381/ges-1billion-software-bet/. 
[8] The innovation in mining: Australia 2016 study. Retrieved from https://www2.deloitte.com/au/en/pages/energy-andresources/articles/innovation-mining.html.

[9] IIoT Technologies and Connected Services. Retrieved from https://www.emersonprocessxperts.com/2016/11/iiottechnologies-and-connected-services/.

[10] Big data and IIOT. Retrieved from http://www.hinditron.com/solutions/big-data-iot/. 